\title{
Erratum to: Dynamics of CMEs in the LASCO Field of View - Statistical Analysis
}

\section{G. Michalek $^{1}$}

Published online: 17 May 2016

(C) Springer Science+Business Media Dordrecht 2016

Erratum to: Solar Phys (2012) 276: 277-291

DOI 10.1007/s11207-011-9895-2

Acknowledgements Grzegorz Michalek was supported by NCN through the grant UMO-2013/09/B/ST9/ 00034.

The online version of the original article can be found under doi:10.1007/s11207-011-9895-2.

\section{G. Michalek}

michalek@oa.uj.edu.pl

1 Astronomical Observatory of Jagiellonian University, Krakow, Poland 